\title{
Mutantes insercionais de Magnaporthe grisea com patogenicidade alterada em arroz
}

\author{
Carlos Eduardo Marchi', Sérgio H. Brommonschenkel ${ }^{2}$, Marisa V. Queiroz ${ }^{3}$, Mírian F. Borges ${ }^{1}$ \& Eduardo \\ S.G. Mizubuti
}

${ }^{1}$ Superintendência Federal de Agricultura - AM, 69057-010, Manaus, AM, Brasil; ${ }^{2}$ Departamento de Fitopatologia; ${ }^{3}$ Departamento de Microbiologia, Universidade Federal de Viçosa, 36570-000, Viçosa, MG, Brasil

Autor para correspondência: Carlos Eduardo Marchi, e-mail: carlos.marchi@agricultura.gov.br

\begin{abstract}
RESUMO
Transformantes de Magnaporthe grisea resistentes a higromicina, obtidos principalmente por procedimentos REMI (Restriction Enzyme-Mediated Integration), foram avaliados quanto à habilidade em causar doença em arroz. A partir de testes de patogenicidade envolvendo 125 transformantes foi possível selecionar cinco mutantes com alterações consistentes na patogênese. Dois desses mutantes, T108 e T93, causaram poucas lesões em folhas de arroz, enquanto o mutante T251 não foi patogênico. A alteração na patogenicidade de T108 foi acompanhada pela menor capacidade de desenvolvimento in vitro. Quando inoculado em plantas de arroz, o mutante T41 apresentou agressividade reduzida, caracterizada por lesões arredondadas de tamanho limitado. Por sua vez, o período de incubação para o mutante T72 foi maior que o do isolado selvagem. Além disso, atraso considerável na germinação de conídios e formação de apressórios foi detectado em T72. Todos os mutantes cresceram em meio mínimo, indicando que as mutações não foram associadas à auxotrofia. Os mutantes T93 e T251 apresentam fenótipos semelhantes quando em cultura, caracterizados pela pigmentação marrom.

Palavras-chave: Pyricularia grisea, . oryzae, brusone, mutagênese insercional, integração mediada por enzima de restrição, REMI, genes de patogenicidade.
\end{abstract}

\begin{abstract}
Insertional mutants of Magnaporthe grisea with changes in their pathogenicity to rice

Hygromycin-resistant transformants of Magnaporthe grisea, generated mainly by REMI (Restriction Enzyme-Mediated Integration), were screened for their ability to infect rice plants. Out of 125 transformants five showed changes in pathogenicity. The T108 and T93 mutants caused few lesions in rice leaves, while the T251 mutant was non-pathogenic. The alteration in pathogenicity of T108 was accompanied by reduced development in culture. The T41 mutant caused small and limited round lesions. The incubation period of the T72 mutant was longer than that of the wild type. Furthermore, late germination and appresorium formation was detected in the T72 mutant. All mutants grew in minimum medium, suggesting that there were no auxotrophic-associated mutations. The T93 and T251 mutants presented similar phenotypes in culture, characterized by a brown-pigmented colony.
\end{abstract}

Keywords: Pyricularia grisea, Pyricularia oryzae, rice blast, insertional mutagenesis, restriction enzyme-mediated integration, REMI, pathogenicity genes.

\section{INTRODUÇÃO}

A brusone, causada por Magnaporthe grisea (Hebert) Barr. (anamorfo: Pyricularia grisea, P. oryzae), é a doença mais importante da cultura do arroz no Brasil, constituindo fator limitante para a produtividade (Prabhu et al., 2002). Os mecanismos genéticos que governam a patogenicidade de $M$. grisea em arroz têm sido intensivamente investigados, visto que a compreensão mais detalhada desse processo poderá auxiliar no delineamento de novas e eficientes estratégias de manejo da doença. Alguns componentes importantes da patogênese estão identificados, principalmente aqueles envolvidos em eventos pré-penetração (Talbot, 1995; Howard \& Valent, 1996; Hamer \& Talbot, 1998; Idnurm \& Howlett, 2001). Porém, pouco se conhece sobre os mecanismos que regulam a colonização do patógeno e os estádios finais da infecção da planta.
A mutagênese insercional constitui estratégia adotada para a identificação de genes de patogenicidade de $M$. grisea (Talbot \& McCafferty, 1997; Balhadère et al., 1999). Destacase a técnica de integração mediada por enzima de restrição ou REMI, Restriction Enzyme-Mediated Integration (Schiestl \& Petes, 1991), a qual tem contribuído eficientemente para gerar mutações no genoma desse ascomiceto (Shi et al., 1995; Shi \& Leung, 1995; Sweigard et al., 1998; Balhadère et al., 1999; Fujimoto et al., 2002). REMI envolve a transformação do organismo com o DNA transformante linear na presença de enzima de restrição, geralmente a mesma utilizada para a linearização do vetor (Sweigard, 1996). O resultado é a formação de extremidades coesivas compatíveis entre o vetor e o DNA genômico, o que aumenta a eficiência de transformação e predominância de integrações simples.

A partir de mutantes insercionais tem sido 
possível a clonagem de genes de $M$. grisea envolvidos na diferenciação de estruturas de infecção, respostas ao ambiente e sinalização celular (Idnurm \& Howlett, 2001). Exemplos dessas classes de genes incluem: 1) PTH11, que codifica para uma proteína transmembrana, envolvida no reconhecimento de superfície e formação de apressório (Sweigard et al., 1998); 2) PTH3, com homologia a imidazol glicerol fosfato dehidratase de Saccharomyces cerevisiae, envolvido na síntese de histidina (Sweigard et al., 1998); 3) PTH9, que expressa uma trehalase neutra, que em outros fungos está envolvida na proteção contra estresse e germinação de esporos (Sweigard et al., 1998); 4) PTH4, que codifica para uma proteína quinase dependente de cAMP, envolvida na função do apressório (Sweigard et al., 1998), 5) $A B C 1$, que codifica para um transportador $\mathrm{ABC}$, possivelmente envolvido na detoxificação de compostos antimicrobianos (Urban et al., 1999), e 6) PDE1, que codifica para uma ATPase tipo P, a qual supostamente atua em papel crítico na formação de hifas de penetração funcionais (Balhadère \& Talbot, 2001). Genes que desempenham função na conidiogênese também foram marcados fisicamente e clonados via mutagênese insercional (Shi \& Leung, 1995; Sweigard et al., 1998; Lau \& Hamer, 1998; Balhadère et al., 1999).

Recentemente, visando à prospecção de novos genes de $M$. grisea que atuam na infecção ao arroz, a mutagênese REMI foi adequada para o emprego do vetor pAN7-1 e a enzima HindIII (Marchi et al., 2006). Tal esforço resultou na criação de uma coleção de transformantes insercionais. O presente trabalho teve como objetivo identificar, a partir dessa coleção, mutantes de $M$. grisea com alterações na patogenicidade em arroz, com a posterior caracterização patogênica, fisiológica e morfológica.

\section{MATERIAL E MÉTODOS}

\section{Magnaporthe grisea e condições de cultivo}

Foi utilizado o isolado I-22 de M. grisea, patogênico a plantas de arroz, gentilmente cedido pelo Laboratório de Fitopatologia Molecular da Universidade Federal do Rio Grande do Sul, Porto Alegre, RS. O fungo foi cultivado em meio de farinha de arroz-ágar (FAA - $20 \mathrm{~g}$ de farinha de arroz com casca, $5 \mathrm{~g}$ de sacarose, $15 \mathrm{~g}$ de ágar, $1 \mathrm{~L}$ de água destilada) por cinco a sete dias, a $28^{\circ} \mathrm{C}$ no escuro. A manutenção dos transformantes de $M$. grisea foi conduzida em meio FAA acrescido de $100 \mu \mathrm{g} / \mathrm{mL}$ de higromicina (Marchi et al., 2006). Para a preservação do fungo por longo prazo, pedaços $\left(4 \mathrm{~cm}^{2}\right)$ de papel manteiga colonizados pelo micélio foram mantidos a $80{ }^{\circ} \mathrm{C}$ (Valent et al., 1991).

A produção de conídios foi obtida após submeter M. grisea a condições de estresse. Para isso, removeuse o micélio superficial de culturas do fungo com 710 dias de idade, com pincel e água destilada. Após enxágüe em água destilada, as placas de cultura foram cobertas com filme plástico transparente perfurado e mantidas em temperatura ambiente por quatro a seis dias, com fotoperíodo de $12 \mathrm{~h}$.

\section{Identificação de mutantes para a patogenicidade}

A coleção de transformantes insercionais de $M$. grisea, obtidos por meio de transformação convencional e, principalmente, por procedimentos REMI (Marchi et al., 2006), foi explorada para a identificação de mutantes com alterações na patogênese ao arroz. Os testes de patogenicidade foram conduzidos com as cultivares Epagri-106 e Epagri-109, gentilmente cedidas pela EPAGRI, SC. Enquanto Epagri-106 é suscetível ao isolado I-22, Epagri-109 é resistente. A semeadura foi realizada em vasos plásticos contendo mistura de solo e substrato Plantmax ${ }^{\circledR}(1: 1)$. As adubações de cobertura foram realizadas conforme recomendações para a cultura.

Os transformantes de $M$. grisea selecionados foram submetidos aos ensaios de patogenicidade em plantas de arroz, sob condições de câmara de crescimento a $26{ }^{\circ} \mathrm{C}$ e fotoperíodo de $12 \mathrm{~h}$. As inoculações foram realizadas em plantas no estádio de três ou quatro folhas ( \pm 21 dias), com suspensão de 1,0 - 1,5 x 105 conídios/ $\mathrm{mL}$. Inicialmente, a seleção foi feita utilizando-se apenas uma repetição (1 vaso com 5 plantas). Os transformantes com possíveis alterações na patogenicidade ou virulência foram selecionados para novo ensaio, com 10 repetições (10 vasos com 5 plantas cada).

A reação das plantas Epagri-106 foi avaliada 10 dias após inoculação, sendo registrados os componentes: período de incubação (PI), número de lesões (NL), formato das lesões (FL), área das lesões (AL) e severidade (S). O PI, tempo decorrido desde a inoculação até o aparecimento dos primeiros sintomas, foi avaliado a cada $8 \mathrm{~h}$, sendo considerado concluído quando $50 \%$ das plantas apresentaram sintomas. As avaliações do NL e FL foram de caráter qualitativo. Transformantes que causaram número reduzido de lesões ou lesões com formatos atípicos foram considerados mutantes para a patogenicidade. Para o cálculo da AL foram amostradas 20 lesões por repetição, mensurando-se o comprimento (C) e a largura (L) das mesmas. A área da lesão foi obtida segundo a fórmula: $\mathrm{AL}\left(\mathrm{mm}^{2}\right)=\pi$ $\times \mathrm{C} / 2 \times \mathrm{L} / 2$. A severidade da doença foi avaliada utilizandose escala diagramática com 10 notas (IRRI, 2002). Plantas da cultivar Epagri-109 foram avaliadas no intervalo de 5-15 dias após inoculação, considerando-se apenas a incidência de brusone.

\section{Estabilidade mitótica}

Os mutantes identificados foram cultivados em placas de Petri contendo meio BDA (200 g de batata, $20 \mathrm{~g}$ de dextrose, $20 \mathrm{~g}$ de ágar, $1 \mathrm{~L} \mathrm{H}_{2} \mathrm{O}$ destilada), sem antibiótico, e permitidos a crescer por sete dias a $28^{\circ} \mathrm{C}$. Concluído o tempo, foram transferidos para outra placa contendo BDA, e assim sucessivamente por cinco gerações. Após as transferências seriadas, testou-se a capacidade de crescimento dos mutantes em BDA contendo $200 \mu \mathrm{g}$ de higromicina/mL. Cada mutante foi repicado para quatro placas de Petri por geração. 


\section{Crescimento in vitro, germinação de conídios e diferenciação de apressórios}

O crescimento do fungo, mensurado como área da colônia $\left(\mathrm{mm}^{2}\right)$, foi avaliado em culturas crescidas em meio completo (MC - BDA) ou meio mínimo (MM - Crawford et al., 1986) a $28^{\circ} \mathrm{C}$, no escuro por 11 e 13 dias, respectivamente. Cada mutante foi repicado para cinco placas de Petri.

A germinação e o desenvolvimento de estruturas de infecção foram monitoradas em epiderme de cebola, conforme protocolo de Balhadère et al. (1999). Brevemente, $20 \mu \mathrm{L}$ de suspensão contendo $10^{5}$ conídios $/ \mathrm{mL}$ foram distribuídos sobre a superfície hidrofóbica da epiderme de cebola, disposta em lâmina de vidro. Prepararam-se quatro lâminas por mutante, as quais foram incubadas em câmara úmida à temperatura ambiente. Durante 20 $\mathrm{h}$ de incubação, as epidermes foram examinadas periodicamente, e a freqüência de conídios germinados e conídios com apressórios determinadas em microscópio de luz, amostrando-se 200 conídios por lâmina.

\section{Definições operacionais}

O processo patogênico de $M$. grisea é complexo e envolve muitos genes. Por convenção, todos os genes requeridos para o desenvolvimento da doença, mas não essenciais para o patógeno completar seu ciclo de vida in vitro, foram aqui mencionados como "genes de patogenicidade" (Idnurm \& Howlett, 2001). O termo "genes de avirulência" ou "AVR" foi empregado para designar alelos de genes do fungo que condicionam a especificidade de hospedeiro em cultivares (Valent et al., 1991). A intensidade da doença durante período determinado de tempo foi referida como "agressividade".

\section{RESULTADOS}

\section{Identificação e caracterização patogênica dos mutantes}

A patogenicidade e virulência de 125 transformantes de $M$. grisea I-22, obtidos por transformação convencional e, principalmente, por REMI, foram avaliadas em plantas de arroz. Nenhum dos transformantes foi capaz de infectar Epagri-109, cultivar resistente ao I-22, indicando que não houve ganho de virulência por mutações em genes AVR. Contudo, foi possível identificar cinco mutantes com alterações consistentes na patogênese a Epagri-106, cultivar suscetível ao I-22, sugerindo a inativação de genes de patogenicidade. Esses mutantes apresentaram fenótipos distintos, os quais não variaram consideravelmente nos ensaios realizados em épocas diferentes (Tabela 1).

Excepcionalmente, plantas de arroz inoculadas com os transformantes T93 ou T108 desenvolveram poucas

TABELA 1 - Características fenotípicas dos mutantes de Magnaporthe grisea I-22 com alterações na patogenicidade em arroz

\begin{tabular}{|c|c|c|c|c|c|c|c|}
\hline \multirow[t]{2}{*}{ Indivíduo } & \multirow[t]{2}{*}{ Fenótipo $^{1}$} & \multicolumn{2}{|c|}{$\begin{array}{l}\text { Crescimento in vitro } \\
\qquad\left(\mathrm{mm}^{2}\right)^{2}\end{array}$} & \multirow[t]{2}{*}{$\begin{array}{c}\text { Germinação } \\
(\%)^{3}\end{array}$} & \multirow[t]{2}{*}{$\begin{array}{l}\text { Apressório } \\
(\%)^{4}\end{array}$} & \multirow{2}{*}{$\begin{array}{l}\text { Área da } \\
\text { lesão } \\
\left(\mathrm{mm}^{2}\right)^{5}\end{array}$} & \multirow[t]{2}{*}{ Severidade ${ }^{6}$} \\
\hline & & MC & MM & & & & \\
\hline I-22 & Tip o selvagem & $3348,23^{7} a$ & $2095,46 \mathrm{a}$ & 91,82 a & $91,92 \mathrm{a}$ & $2,26 \mathrm{a}$ & 8 \\
\hline T41 & $\begin{array}{l}\text { Lesões de menor } \\
\text { tamanho }\end{array}$ & $4256,47 \mathrm{a}$ & $2697,26 \mathrm{a}$ & 93,93 a & 90,46 a & $0,34 \mathrm{~b}$ & 3 \\
\hline T93 & Raras lesões & $3945,53 \mathrm{a}$ & $2915,84 \mathrm{a}$ & 90,38 a & 87,30 a & $1,95 \mathrm{a}$ & $\mathrm{NA}^{9}$ \\
\hline T108 & Raras lesões & $897,71 \mathrm{~b}$ & $222,23 \mathrm{~b}$ & 88,42 a & 89,86 a & $0,67 \mathrm{~b}$ & NA \\
\hline T251 & Não patogênico & $3481,91 \mathrm{a}$ & 1999,46 a & 89,85 a & 89,57 a & NA & NA \\
\hline T72 & $\begin{array}{l}\text { Desenvolvimento } \\
\text { retardado }\end{array}$ & $\mathrm{ND}^{8}$ & ND & $28,18 \mathrm{~b}$ & $0 \mathrm{~b}$ & ND & ND \\
\hline
\end{tabular}

${ }^{1}$ Fenótipo predominante quando inoculado em plantas da cv. Epagri-106. Avaliação aos 10 dias após inoculação.

${ }^{2}$ Área da colônia em meio completo (MC - BDA) ou meio mínimo (MM) aos 11 e 13 dias de incubação a $28{ }^{\circ} \mathrm{C}$, respectivamente.

${ }^{3}$ Porcentagem de conídios germinados em epiderme de cebola, com $2 \mathrm{~h}$ de incubação a temperatura ambiente.

${ }^{4}$ Porcentagem de conídios com apressórios diferenciados, em epiderme de cebola, com $8 \mathrm{~h}$ de incubação a temperatura ambiente.

${ }^{5}$ Área da lesão $=\pi \mathrm{x}$ (comprimento da lesão/2) x (largura da lesão/2).

${ }^{6}$ Nota 3 = pequenas lesões arredondadas ou ligeiramente alongadas, com centro cinzento, borda marrom, com n⿳o significativo de lesões nas folhas superiores; Nota $8=51$ - $75 \%$ da área foliar lesionada e presença de muitas folhas mortas (IRRI, 2002).

${ }^{7}$ Valores correspondem a médias, as quais seguidas da mesma letra na coluna não diferem pelo teste de Tukey a $5 \%$.

${ }^{8}$ Não determinado.

${ }^{9}$ Não aplicável. 
lesões típicas da brusone. Em geral, tais transformantes não incitaram sintomas da doença nas plantas (Figura 1B). Quando lesões de T108 foram detectadas em Epagri-106, essas apresentaram áreas reduzidas, média de $0,67 \mathrm{~mm}^{2}$, em relação às lesões de $2,26 \mathrm{~mm}^{2}$ observadas em plantas inoculadas com o isolado selvagem (Tabela 1). O mutante T93 foi obtido por procedimentos REMI, sendo que a integração do vetor foi mediada por $50 \mathrm{U}$ de HindIII. Já o mutante T108 foi gerado por transformação convencional envolvendo pAN7-1 linearizado e a inativação da enzima usada para clivagem do vetor.

Inicialmente, o processo de doença desencadeado por T41 foi semelhante ao observado no indivíduo selvagem, sendo possível a visualização dos primeiros sintomas 64 $h$ após a inoculação. No entanto, o desenvolvimento dos sintomas foi alterado (Figura 1A). Não foram observados halos cloróticos circundando as lesões, as quais foram atípicas, apresentando formatos arredondados e, além disso, áreas reduzidas, média $0,34 \mathrm{~mm}^{2}$ (Figuras 1B-D; Tabela 1). O mutante T41 foi gerado por procedimentos convencionais de transformação, não havendo a inativação da enzima de restrição utilizada para a linearização de
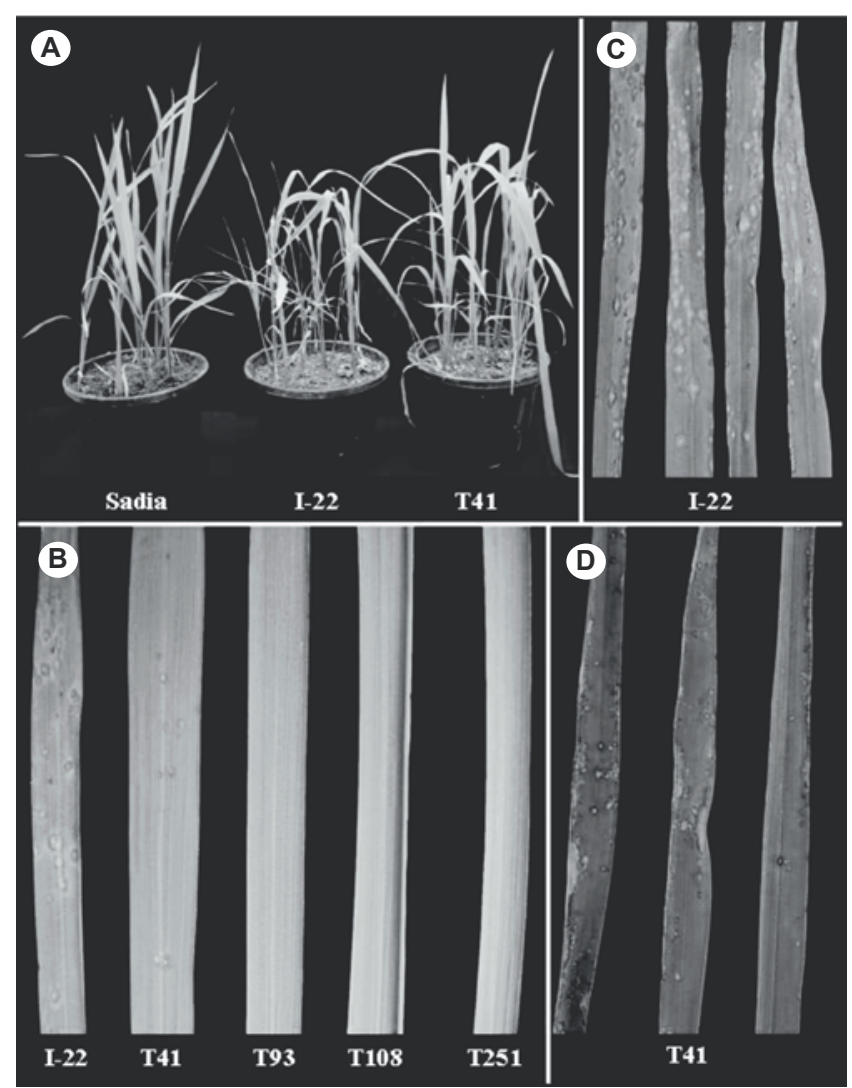

FIG. 1 - Patogenicidade de mutantes de Magnaporthe grisea I-22 em plantas de arroz cv. Epagri-106. A. Aspecto geral de plantas inoculadas com I-22 ou T41. B. Folhas inoculadas com os mutantes. C e D. Detalhes das lesões causadas por I-22 e T41 em estágio avançado, respectivamente.
pAN7-1. Um mutante não patogênico, T251, foi obtido com a transformação REMI envolvendo $30 \mathrm{U}$ de HindIII. Em todas as inoculações, o mutante T251 não infectou Epagri106 (Figura 1B).

As características do mutante T72 foram diferentes dos demais. Plantas inoculadas com T72 desenvolveram menor número de lesões (Figuras 2B-C), e apresentaram atraso no desenvolvimento dos sintomas (Figura 2A). Enquanto I-22 completou o PI com aproximadamente $64 \mathrm{~h}$, T72 apresentou PI mais longo, com cerca de 88 h. O T72 foi gerado pela transformação de I-22 com pAN7-1 linear na presença de atividade residual de HindIII, usada para a linearização.

\section{Estabilidade mitótica dos mutantes}

A estabilidade mitótica dos mutantes T41, T93, T108 e T251 foi avaliada cultivando-os sucessivamente em meio de cultura sem o agente de seleção. Após cinco gerações de cultivo nessas condições, cerca de 35 dias, os mutantes foram transferidos para o meio seletivo. Todos os mutantes foram resistentes ao antibiótico higromicina, indicando que as integrações de pAN7-1 no genoma do ascomiceto foram mitoticamente estáveis. Quando plantas de arroz foram inoculadas com T41, T93, T108 ou T251, oriundos da última geração de cultivo do ensaio de estabilidade mitótica, verificaram-se os mesmos fenótipos apresentados na Figura 1.

\section{Crescimento in vitro, germinação de conídios e diferenciação de apressórios}

O efeito das mutações no crescimento vegetativo dos mutantes T41, T93, T108 e T251 foi estudado. O crescimento dos mutantes T41, T93 e T251 em MC foi semelhante ao crescimento do indivíduo selvagem. Em contrapartida, o mutante T108 teve crescimento reduzido, cerca de $73 \%$ menor que o crescimento de I-22 (Tabela 1; Figura 3). O padrão de crescimento dos mutantes em MM foi semelhante ao observado no cultivo em MC (Tabela 1). Quando cultivado in vitro, o mutante T93 apresentou pigmentação marrom, em contraste com a coloração negra da cultura do isolado selvagem (Figura 3). O fenótipo pigmentação manifestado por culturas do mutante T251 foi semelhante ao observado em culturas T93. Os mutantes T93 e T251 foram obtidos em ensaios REMI independentes.

Ensaios em epiderme de cebola foram realizados para avaliar a germinação de conídios e a diferenciação de apressórios (Figura 4). Com duas horas de incubação foi possível observar cerca de $92 \%$ de germinação dos conídios de I-22 (Tabela 1). Também foi possível observar a germinação dos conídios de todos os mutantes, a qual variou de 88 a 94\%, exceto para o mutante T72, o qual apresentou germinação média de $28 \%$. Após $8 \mathrm{~h}$ de incubação dos conídios, foi possível constatar diferenciação de apressórios em I-22 da ordem de $92 \%$. As porcentagens de diferenciação de apressórios dos mutantes T41, T93, T108 e T251 foram semelhantes, variando de 87 a 90\% (Tabela 1). Nenhum apressório foi formado pelo mutante T72 após $8 \mathrm{~h}$ de 


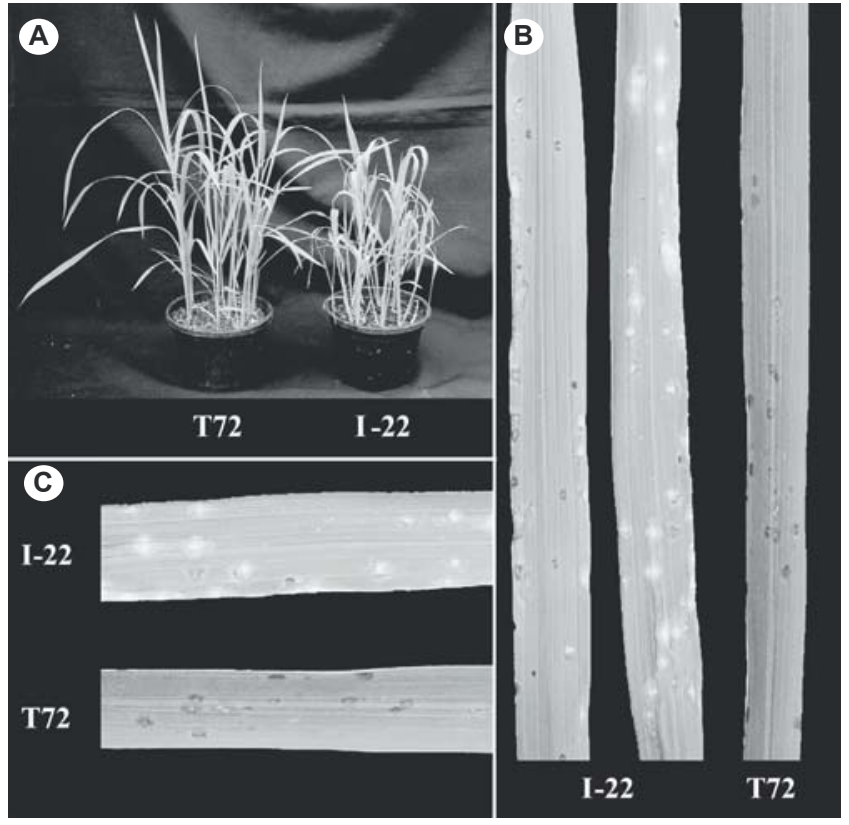

FIG. 2 - Patogenicidade do mutante T72 de Magnaporthe grisea I22 em plantas de arroz cv. Epagri-106. A. Aspecto geral de plantas inoculadas com I-22 ou T72. B e C. Detalhes das lesões causadas por T72.

incubação. Somente com 20 h de incubação T72 apresentou mais de $50 \%$ de conídios germinados $(54 \%)$, porém a formação de apressórios permaneceu baixa (24,5\%).

Ao microscópio de luz, os apressórios produzidos por I-22 foram robustos, bem definidos e melanizados (Figura 4A). Embora tenha sido comum a ocorrência de apressórios aparentemente anormais em todos os mutantes, houve fração considerada desta classe de apressórios no mutante T93 (Figuras 4C-D). Grande parte dos apressórios formados por T93 apresentou forma irregular, diferente da observada em I-22 (Figura 4A). Embora em menor proporção, apressórios com formas irregulares também foram comuns em T251 (Figura 4F). Os apressórios de T72, apesar de demorarem mais tempo para serem diferenciados (Figura 4G), foram morfologicamente normais, muito similares aos apressórios de I-22 (Figura 4H).

\section{DISCUSSÃO}

Da coleção de 500 transformantes insercionais de $M$. grisea I-22, principalmente gerados por mutagênese REMI, 125 foram avaliados quanto à patogenicidade e à virulência em plantas de arroz. Inoculações foram realizadas em Epagri109, a qual é resistente ao isolado I-22, visando identificar genes AVR de $M$. grisea envolvidos na especificidade de cultivares. Contudo, nenhum transformante foi capaz de infectar essa cultivar, o que provavelmente ocorreu devido ao número reduzido de indivíduos analisados. A carência de informações sobre a base genética da resistência no hospedeiro também dificultou a detecção de mutantes virulentos. A presença de mais de um gene de resistência (R) em Epagri-109, prevenindo a infecção pelo isolado I-22, tornaria mais árdua a identificação de genes AVR. Segundo a hipótese, sustentada pela teoria gene-a-gene (Flor, 1971), seriam necessárias as inativações de todos os genes AVR do fungo cujos produtos estariam relacionados com os produtos dos genes R presentes em Epagri-109.

Foram obtidos mutantes com alterações na patogenicidade em plantas Epagri-106, a qual é suscetível ao I-22. Cinco transformantes apresentaram fenótipo de patogenicidade alterado consistentemente. Surpreendentemente, a recuperação de $4 \%$ de mutantes para a patogenicidade foi elevada em comparação aos índices relatados em trabalhos anteriores. Mutações insercionais em genes de patogenicidade de $M$. grisea, envolvendo a mutagênese REMI, têm sido identificadas em 0,4 a $0,5 \%$ dos transformantes analisados (Sweigard et al., 1998; Balhadère et al., 1999). Um dos fatores associados à maior eficiência correspondeu aos métodos empregados. As pesquisas de Sweigard et al. (1998) e Balhadère et al. (1999) foram conduzidas com cevada. Enquanto os primeiros autores utilizaram sistema inicial de seleção onde as condições não foram controladas completamente, Balhadère et al. (1999) fizeram seleção inicial em folhas destacadas. Como resultado, as condições experimentais podem ter reduzido a identificação de mutantes. A utilização de folhas destacadas pode, por exemplo, ter prejudicado a detecção dos mutantes com alterações no processo de adesão ao hospedeiro.

O estabelecimento da doença no hospedeiro é processo complexo, onde muitas estruturas e moléculas estão envolvidas. Os mutantes identificados, provavelmente, tiveram genes importantes para diferentes etapas da patogênese inativados. Em determinadas ocasiões, o mutante T108, por exemplo, não foi patogênico ao arroz. Além disso, quando cultivado em MC e comparado com I22 , apresentou crescimento vegetativo reduzido em $73 \%$. Em outras ocasiões, T108 causou doença, porém foi menos agressivo, provocando nas folhas lesões com tamanhos reduzidos, o que foi condizente com o menor crescimento em meio de cultura. Fujimoto et al. (2002) recuperaram um mutante insercional semelhante a T108, denominado pat 194 , o qual apresentou crescimento radial reduzido, porém com germinação e esporulação aparentemente normais. Contudo, a caracterização detalhada do gene inativado em pat 194 ainda não foi reportada.

Componente essencial para patogenicidade de M. grisea é a melanina. Este pigmento está diretamente relacionado com a função do apressório. Mutações em genes envolvidos na biossíntese de melanina resultam em perda de patogenicidade (Talbot, 1995; Howard \& Valent, 1996). O mutante T251 não foi patogênico, e a sua pigmentação marrom, quando em cultura, sugeriu uma possível alteração na rota biossintética de melanina. O tubo germinativo de T251 diferenciou o apressório, o que sustenta a hipótese de alteração funcional desta estrutura de infecção. O mutante T93 também apresentou coloração marrom quando cultivado 


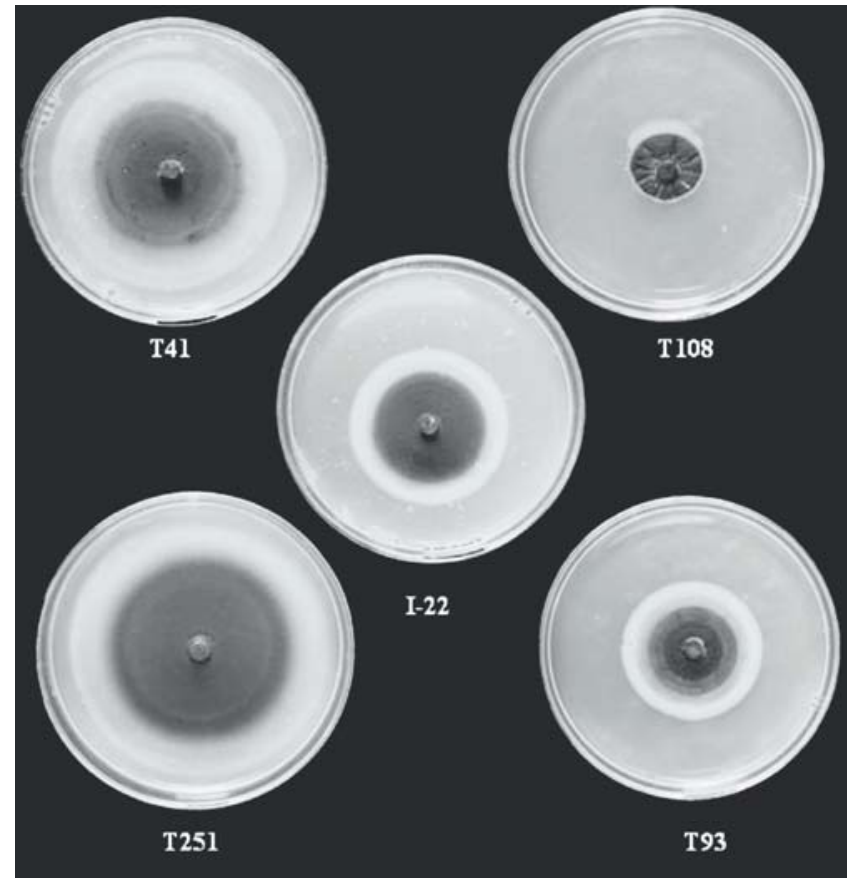

FIG. 3 - Mutantes de Magnaporthe grisea I-22 cultivados em meio completo (MC - BDA), 11 dias após a repicagem. O mutante T108 apresentou crescimento vegetativo reduzido, enquanto os mutantes T93 e T251 apresentaram pigmentação marrom.

in vitro, indistinguível de T251. O mutante T93, apesar de capaz de diferenciar apressórios, apresentou elevada proporção de estruturas com formas irregulares, o que pode ter contribuído para o fracasso no estabelecimento de doença. Alterações morfológicas de apressórios podem ser devido à perda da rigidez da célula, ou devido à inabilidade de gerar turgor (Howard et al., 1991, citados por Talbot \& McCafferty, 1997).

Os mutantes T251 e T93 foram gerados por procedimentos REMI independentes. Alguns relatos apontam para REMI mediando integrações no mesmo gene (Lu et al., 1994; Sweigard et al., 1998). Contudo, ainda é polêmica a aleatoriedade dos eventos de integração em REMI. A análise das seqüências interrompidas em T251 e T93 poderá gerar novas evidências para a discussão.

Ao contrário dos demais, o T72 não apresentou alterações morfológicas visíveis. Das características avaliadas, a única que divergiu de I-22 foi o período de incubação. Comparado ao I-22, T72 apresentou período de incubação mais longo. O T72 também precisou de tempo maior para germinar os conídios e diferenciar os apressórios em epidermes de cebola. Considera-se que T72 é exemplo raro de mutante de $M$. grisea com alterações no período de incubação. A caracterização morfológica, fisiológica e patogênica mais detalhada de T72 encontra-se em progresso.

A maior parte das investigações sobre a patogenicidade de $M$. grisea resultou no acúmulo de informações acerca dos eventos pré-penetração e penetração (Talbot, 1995; Howard \& Valent, 1996; Hamer \& Talbot, 1998; Idnurm \& Howlett, 2001). Talvez por conseqüência do número grande de genes que certamente estão envolvidos e da maior facilidade de identificação de mutantes para estas características. Alguns eventos que antecedem a penetração do fungo envolvem a diferenciação de estruturas especiais de infecção e o acúmulo de melanina nas paredes do apressório. Defeitos em ambas as etapas resultariam em fenótipo não patogênico. Os mutantes aqui descritos ilustraram essa realidade: dos cinco identificados, três mutantes apresentaram dificuldades em iniciar o processo patogênico. Hipoteticamente, é possível que os mutantes T93, T108 e T251 tenham apresentado problemas na diferenciação ou na função do apressório.

Pouco é conhecido sobre a fisiologia do crescimento invasivo de $M$. grisea, da regulação do crescimento no interior dos tecidos do hospedeiro ou sobre os estádios finais da infecção. A agressividade reduzida de T41 pode representar uma fonte para ampliar o conhecimento da maquinaria pós-penetração que rege a patogenicidade do ascomiceto. As dimensões dos bordos marromavermelhados em lesões causadas por $M$. grisea estão relacionadas com o grau de resistência do hospedeiro, sendo estas estreitas em cultivares suscetíveis (Ou, 1985; Bedendo, 1997). Sendo assim, os bordos proeminentes detectados em plantas de arroz inoculadas com T41 constituíram indicativo da dificuldade deste mutante em superar possíveis reações de defesas da planta. Urban et al. (1999) também identificaram um mutante de M. grisea aparentemente incapaz de superar as defesas do hospedeiro. O gene $A B C 1$, assim designado, foi clonado e codifica um transportador $A B C$, o qual supostamente atua como bomba de efluxo para detoxificação de compostos antimicrobianos sintetizados pelo arroz.

Lesões causadas por T41 nunca foram circundadas por halos cloróticos. Tais áreas são caracterizadas por infiltrações de substâncias tóxicas secretadas pelo fungo (Yoshii, 1937, citado por Ou, 1985), e denotam o avanço da infecção (Talbot, 1995). Se a patogênese de T41 foi realmente dificultada pela ausência de compostos fitotóxicos, estes podem atuar como fatores de patogenicidade em estádios mais avançados, embora pareçam ser irrelevantes nos estádios iniciais da doença (Hamer \& Talbot, 1998).

O mutante T108 pode constituir outra ferramenta para a identificação de genes de patogenicidade que atuam na expressão dos sintomas da doença, pois quando foi patogênico causou sintomas com menor intensidade. Apesar de intensamente explorada em $M$. grisea, a mutagênese insercional permanece uma estratégia eficiente para a prospecção de novos genes de patogenicidade. Mutantes de $M$. grisea com alterações expressivas no processo patogênico ao arroz foram identificados, os quais poderão contribuir para o acúmulo de informações acerca do ascomiceto. 

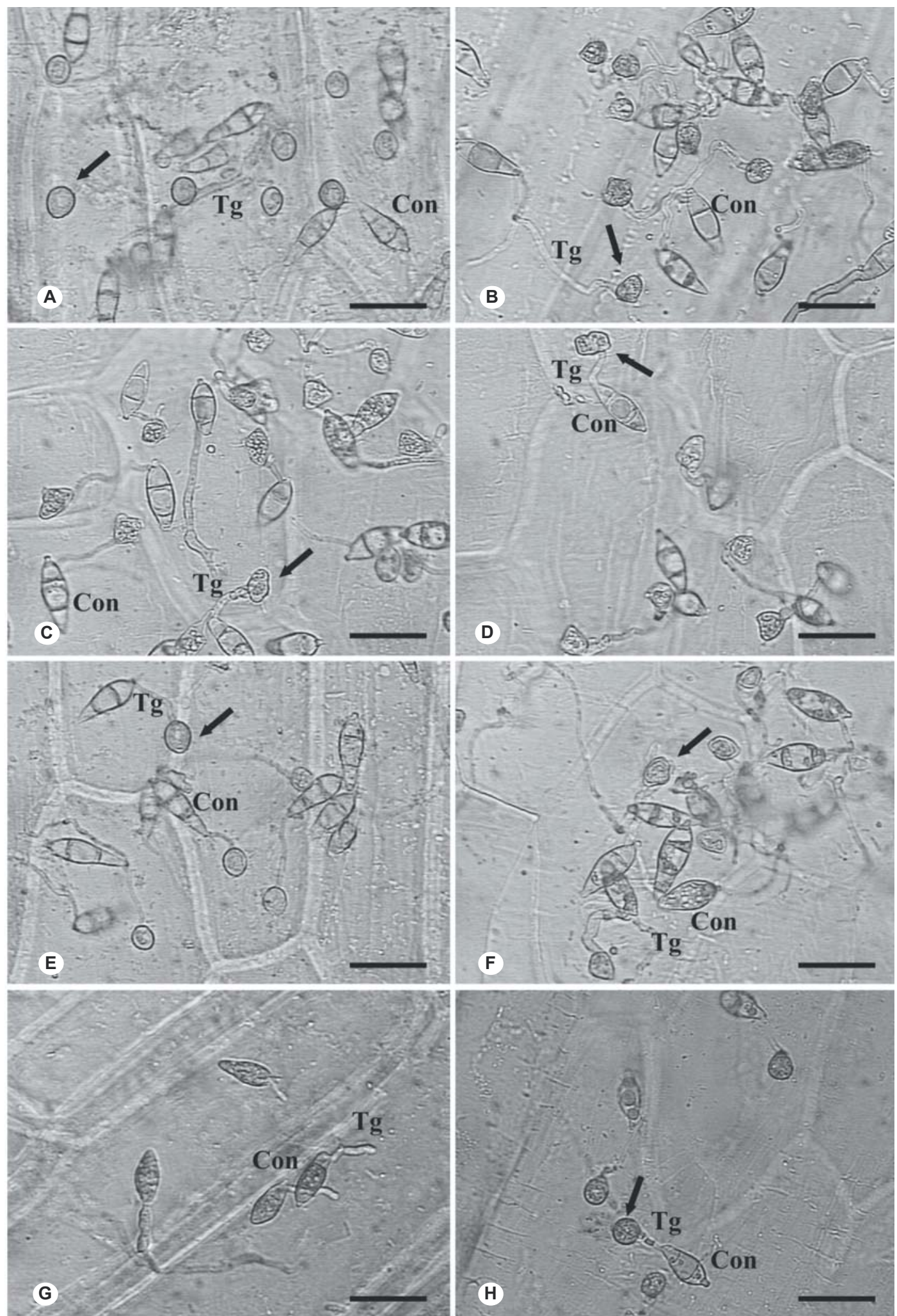

FIG. 4 - Diferenciação e morfologia dos apressórios de mutantes de Magnaporthe grisea I-22, em epiderme de cebola. A: I-22. B: T41. C e D: T93. E: T108. F: T251. G e H: T72. A a G e H com 8 e 20 h de incubação, respectivamente. Con: Conídio. Tg: Tubo germinativo. Setas indicam a presença de apressórios. Barras equivalem a $20 \mu \mathrm{m}$. 


\section{REFERÊNCIAS BIBLIOGRÁFICAS}

Balhadère PV, Talbot NJ (2001) PDE1 encodes a P-type ATPase involved in appressorium-mediated plant infection by the rice blast fungus Magnaporthe grisea. The Plant Cell 13:1987-2004.

Balhadère PV, Foster AJ, Talbot NJ (1999) Identification of pathogenicity mutants of the rice blast fungus Magnaporthe grisea by insertional mutagenesis. Molecular Plant-Microbe Interactions $12: 129-142$

Bedendo IP (1997) Doenças do arroz. In: Kimati H, Amorim L, Bergamin Filho A, Camargo LEA, Rezende JAM (Eds.) Manual de Fitopatologia, Vol. 2. Doenças das plantas cultivadas. 3를 ed. São Paulo SP. Editora Agronômica Ceres Ltda. pp. 84-87.

Crawford MS, Chumley FG, Weaver CG, Valent B (1986) Characterization of the heterokaryotic and vegetative diploid phases of Magnaporthe grisea. Genetics 114:1111-1129.

Flor HH (1971) Current status of the gene-for-gene concept. Annual Review of Phytopathology 9:275-296.

Fujimoto D, Shi Y, Christian D, Mantanghihan JB, Leung H (2002) Tagging quantitative loci controlling pathogenicity in Magnaporthe grisea by insertional mutagenesis. Physiological and Molecular Plant Pathology 61:77-88.

Hamer JE, Talbot NJ (1998) Infection-related development in the rice blast fungus Magnaporthe grisea. Current Opinion in Microbiology 1:693-697.

Howard RJ, Valent B (1996) Breaking and entering: host penetration by the fungal rice blast pathogen Magnaporthe grisea. Annual Review in Microbiology 50:491-512.

Idnurm A, Howlett BJ (2001) Pathogenicity genes of phytopathogenic fungi. Molecular Plant Pathology 2:241-255.

Irri (2002) Standard evaluation system for rice (SES). Los Baños. International Rice Research Institute.

Lau GW, Hamer JE (1998) Acropetal: A genetic locus required for conidiophore architecture and pathogenicity in the rice blast fungus. Fungal Genetics and Biology 24:228-239.

Lu S, Lyngholm L, Yang G, Bronson C, Yoder OC, Turgeon BG (1994) Tagged mutations at the Tox 1 locus of Cochliobolus heterostrophus by restriction enzyme-mediated integration. Proceedings of the National Academy of Sciences of the USA 91:12649-12653.
Marchi CE, Brommonschenkel SH, Queiroz MV, Mizubuti ESG (2006) Integração de pAN7-1 no genoma de Magnaporthe grisea mediada por enzima de restrição. Fitopatologia Brasileira 31:254260.

Ou SH (1985) Rice Diseases. 2. ed. Kew: Commonwealth Mycological Institute.

Prabhu AS, Guimarães CM, Silva GB (2002) Manejo da brusone no arroz de terras altas. Santo Antônio de Goiás GO. Embrapa Arroz e Feijão. Circular Técnica 52.

Schiestl RH, Petes TD (1991) Integration of DNA fragments by illegitimate recombination in Saccharomyces cerevisiae. Proceedings of the National Academy of Sciences of the USA 88:7585-7589.

Shi Z, Leung H (1995) Genetic analysis of sporulation in Magnaporthe grisea by chemical and insertional mutagenesis. Molecular Plant-Microbe Interactions 8:949-959.

Shi Z, Christian D, Leung H (1995) Enhanced transformation in Magnaporthe grisea by restriction enzyme-mediated integration of plasmid DNA. Phytopathology 85:329-333.

Sweigard J. (1996) A Remi primer for filamentous fungi. International Society for Molecular Plant-Microbe Interactions Reporter. Spring. pp. 3-5.

Sweigard JA, Carroll AM, Farrall 1, Chumley FG, Valent B (1998) Magnaporthe grisea pathogenicity genes obtained through insertional mutagenesis. Molecular Plant-Microbe Interactions 11:404-412.

Talbot NJ, McCafferty HRK (1997) Identification and characterisation of pathogenicity genes from the rice blast fungus Magnaporthe grisea. Cahiers Options Méditerranéennes 15:137142.

Talbot NJ (1995) Having a blast: exploring the pathogenicity of Magnaporthe grisea. Trends in Microbiology 3:9-16.

Urban M, Bhargava T, Hamer JE (1999) An ATP-driven efflux pump is a novel pathogenicity factor in rice blast disease. The EMBO Journal 18:512-521.

Valent B, Farrall L, Chumley FG (1991) Magnaporthe grisea genes for pathogenicity and virulence identified through a series of backcrosses. Genetics 127:87-101.

Recebido 1 Agosto 2006 - Aceito 27 Novembro 2007 - TPP 6086 Editor Associado: Álvaro M.R. Almeida 